\title{
Synthesis, Crystal Structure and Property Studies on a Tetrachlorocuprate Salt of an Organic Cation
}

\author{
Fang Fang Jian, Yong Qi Qin, Jing Zhang, and Pu Su Zhao \\ New Haterials \& Function Coordination Chemistry Laboratory, Oingdao University of Science and Technolog, \\ Qingdao, Shandong 266042, P.R. China. E-mail: shaopusual63.com \\ Received April 25, 2008
}

Key Words : Sỵnthesis. Crystal structure. Fluorescence spectra. Thennal stability

Organic-inorganic hybrids provide an exciting opportunity to combine useful attributes of organic and inorganic materials within a single molecular scale composite. Thus. organic-inorganic salts become a relatively large structural family in which a number of interesting magnetic. optical. and electrical phenomena have been observed. ${ }^{1-4}$ Among numerous robust and flexible synthetic strategies to obtain organic-inorganic salts. Orpen and Branumer groups $s^{+66}$ have used salts of anionic metal complexes with peripheral hydrogen-bond acceptor capability (and no hydrogen-bond donors) in which the relative orientation and location of the ions is controlled at least in part by $\mathrm{M}-\mathrm{Cl} \cdots \mathrm{HN}(\mathrm{M}=\mathrm{Pt} . \mathrm{Pd})$ hydrogen bonding. This strategy affords diversity through modularity. with a wide variety of ions of various shapes. charges. and properties being available to replace either a cation or an anion. For example. Orpen group explored the consequences on the structures as a result of modifying the geometries of the anion (monatomic Cl- square planar. trigonal bipyramidal. octahedral. and polymeric) ${ }^{7-9}$ the type and orientation of the ligand hydrogen-bond acceptors, ${ }^{11,11}$ and the location of the cation $\mathrm{NH}$ groups. ${ }^{12}$ Recently. our group obtained a tetraclulorocuprate salt of an organic cation. $\left[\text { DBPMFH }_{2}\right]^{\hat{2}}\left[\mathrm{CuCl}_{4}\right]^{--} \cdot \mathrm{H}_{2} \mathrm{O}$ \{DBPMF $=2,7$-dibromo-9,9(4-pyridylmethyl)fluorine), where $\mathrm{Cu}-\mathrm{Cl} \cdots \mathrm{HN}$ hydrogen bonding helps to form net works and stabilize the molecular structure. Herein. we wish to report the synthesis. crystal

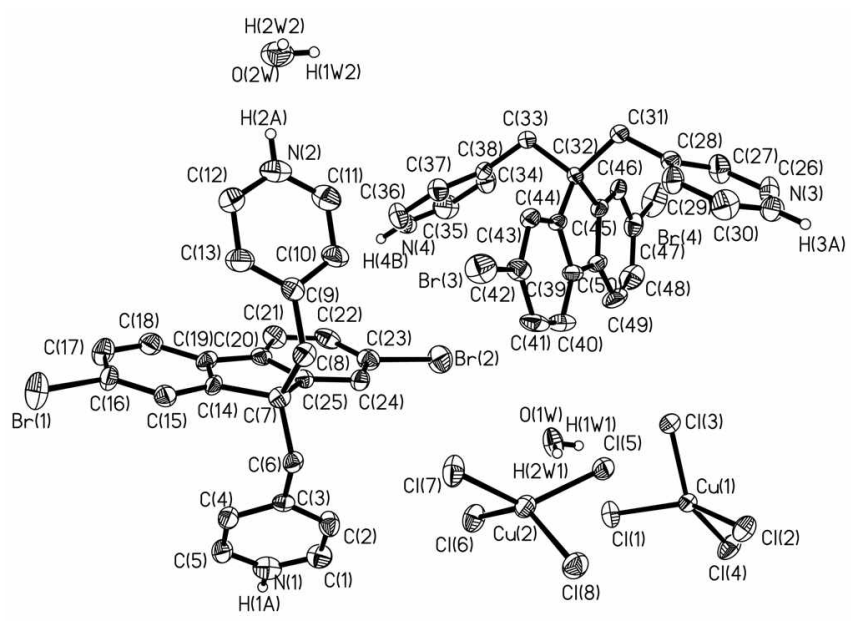

Figure 1. Molecular structure for the title compound with the atomic numbering scheme. structure. fluorescence and thermal stability of $\left[\mathrm{DBPMFH}_{2}\right]^{\hat{i}^{-}}$ $[\mathrm{CuCl} 4]^{\hat{-} \cdot} \cdot \mathrm{H}_{2} \mathrm{O}$.

Crystal structure of the title complex [DBPMFH. $]^{2-}$ $[\mathrm{CuCl} 4]^{i^{--}} \cdot \mathrm{H}_{2} \mathrm{O}$ crystallizes in orthorhombic system. space group Pbca. with lattice parameters $a=22.720(4) \AA . b=$ $18.070(4) \AA, c=27.590(5) \AA . V=11327(4) \AA^{3}, M r=731.60$ $\left(\mathrm{C}_{25} \mathrm{H}_{22} \mathrm{Br}_{2} \mathrm{Cl}_{4} \mathrm{CuN}_{2} \mathrm{O}\right), Z=16, D c=1.716 \mathrm{~g} / \mathrm{cm}^{2} . \mu=3.993$ $\mathrm{mm}^{-1} \cdot F(000)=5776 . \mathrm{GOF}=0.939 \cdot R_{1}=0.0592 \cdot w R_{2}=$ 0.0899 . A displacement ellipsoid plot. with the atomic numbering scheme. is shown in Figure 1.

The structure of the title compound contains a pair of crystallographically independent $\left[\mathrm{DBPMFH} \mathrm{H}_{2}\right]^{2-}\left[\mathrm{CuCl}_{4}\right]^{3-}$ salts and two water molecules in the asymmetric unit. All of the bond lengths and bond angles in the protonated $\left[\mathrm{DBPMFH} \mathrm{H}_{2}\right]^{3+}$ cation are in the norntal range. As for the two independent $\left[\mathrm{CuCl}_{4}\right]^{3-}$ anions. both the $\mathrm{Cu}^{3+}$ ions adopt obviously distorted tetrahedron conformations. All of the bond angles of $\mathrm{Cl}-\mathrm{Cll}-\mathrm{Cl}$ differ significantly from tetrahedral angle $\left(109.48^{\circ}\right)$ and vary from $94.22(7)$ to $146.26(8)^{\circ}$. This phenomena can also be found in the similar organic-inorganic salts of bis[cinchoninium tetrachlorocuprate(II)] trihydrate ${ }^{13}$ and bis-dipropylanmonium tetrachlorocuprate (II). ${ }^{14}$ In the title compound. all of the bond lengths of $\mathrm{Cu}-\mathrm{Cl}$ $[2.2102(18)-2.2735(18) \AA]$ are comparable to the similar organic-inorganic salts cited above.

The most notable structure feature of the title compound is that there are many types of the intramolecular and intermolecular hydrogen bonds. potential weak $\mathrm{C} \cdot \mathrm{H} \cdots \mathrm{Cl}(\mathrm{Br}) . \mathrm{C}$ $\mathrm{H} \cdots \pi$ intermolecular interactions and $\pi \cdots \pi$ stacking interactions between the molecules. Among all of the intermolecular interactions, hydrogen bonds of $\mathrm{N} \cdot \mathrm{H} \cdot \mathrm{Cl}-\mathrm{Cu} . \mathrm{N}-\mathrm{H} \cdot \cdots$ $\mathrm{O}$ and $\mathrm{O}-\mathrm{H} \cdots \mathrm{Cl}-\mathrm{Cu}$ make the two water molecules, two $\left[\mathrm{CuCl}_{4}\right]^{3-}$ anions and two $\left[\mathrm{H}_{2} \text { DBPMF }\right]^{2^{-}}$cations to form a short chain as shown in Figure 2. In the crystal lattice. these chains are staggered each other to form 3-dimension networks. All of the hydrogen bonds, intermolecular interactions and $\pi \cdots \pi$ stacking interactions stabilize the molecular structure.

Fluorescence spectra of the title complex were measured on a F96-fluorospectrophotometer in DMF solution. as shown in Figure 3. which displays a broad emission band with the maximum intensity at $\lambda=367 \mathrm{~nm}$ in the DMF solution upon excitation at $\lambda=365 \mathrm{~mm}$.

Figure 4 gives the thermal analysis curve of the title compound. In Figure 4, there are mainly two exothermal peaks. 


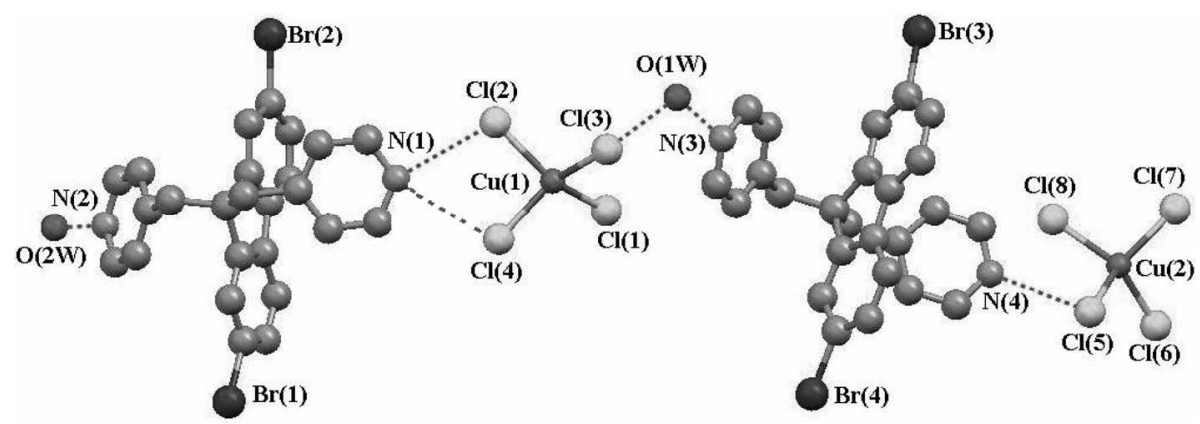

Figure 2. Short chain built through hydrogen bonds for the title compound.

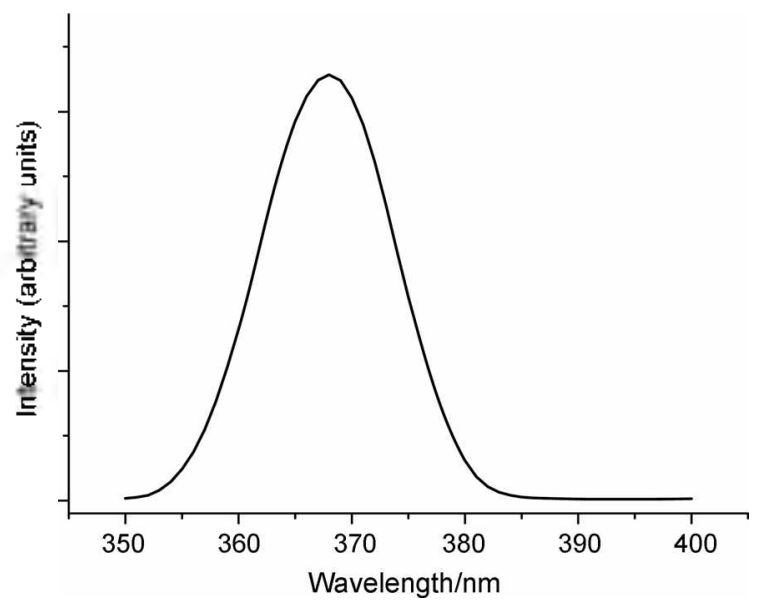

Figure 3. Fluorescence emission spectra of the title compound in DMF solution.

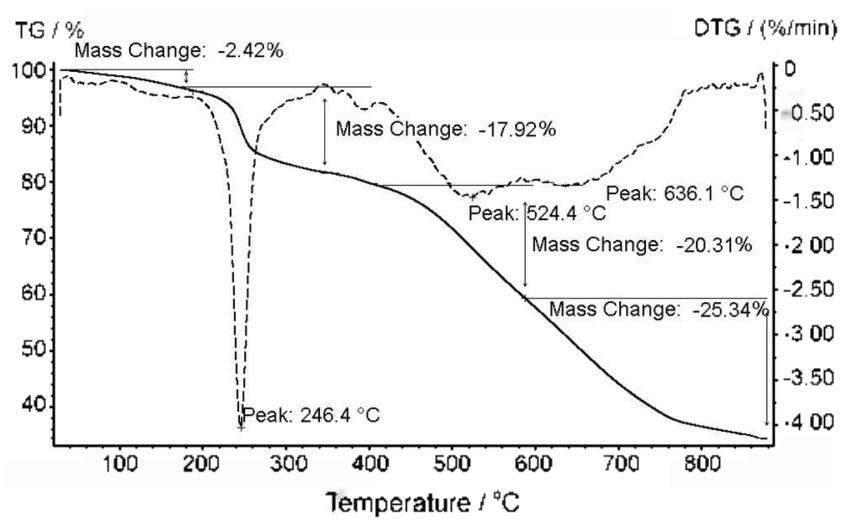

Figure 4. The thenmal analysis curve of the title componnd.

one is a sharp peak at $246.4^{\circ} \mathrm{C}$ and another is a continuous broad peak from 524.4 to $636.1^{\circ} \mathrm{C}$, corresponding to two weight-loss processes. The title compound exhibits the first weight loss $(20.34 \%)$ at $100-360^{\circ} \mathrm{C}$. which is approximately corresponding to the loss of one water molecule and four $\mathrm{Cl}$ atoms (calcd. $21.85 \%$ ). The second weight loss (45.65\%) occurs at $360-820{ }^{\circ} \mathrm{C}$. which is attributed to the lose of $\left[\mathrm{H}_{2} \mathrm{DBPMF}\right]^{2+}$ cation except two $\mathrm{Br}$ atoms (calcd. $47.54 \%$ ). The residue may be $\mathrm{CuBr}_{2}$ (calcd. $30.61 \%$ ).

\section{Experimental Section}

Preparation of the intermediate 2,7-dlibromo-9,9-(4pyridyl-methyl)fluorene [DBPMF]. The reaction path is shown in Scheme 1. 2,7-Dibromofluorene (0.1 mol) and 4chloromethyl pyridine hydrochloride $(0.2 \mathrm{~mol})$ were nixed in DMSO $(70 \mathrm{~mL})$ with stirring at room temperature. Addition of the powders of $\mathrm{KOH}(0.55 \mathrm{~mol})$ to the resulting mixture produced a viscid solution. After $3 \mathrm{l}$, the reaction was stopped and the mixtures were poured into $200 \mathrm{~mL} \mathrm{cool}$ water and stirred fleetly. After filtering and drying, the white products were obtained. Yield: $99 \%$. mp. 136-137 ${ }^{\circ} \mathrm{C} .{ }^{1} \mathrm{H}$ NMR (400 MHz. DMSO) $\delta 3.20(\mathrm{~s}, 2 \mathrm{H}$ ). 7.25-7.28 (d. $4 \mathrm{H}$ ), 7.55-7.57(d, 2H). 7.53-7.56 (d. $4 \mathrm{H}), 8.60-8.64$ (d, $4 \mathrm{H})$; IR: $v$ 3329 (vs). 3172 (vs). 3106 (vs). 1672 (vs). 1573 (vs). 1466 (v), 1425 (s). 1283 (vs), 1028 (s). 1002 (m), 962 (w). 871 (w) 597 (m). 472 (w) $\mathrm{cm}^{-1}$. Found: C. $59.12:$ H. $3.19 ; \mathrm{N}$, $5.38 \%$. Calc. for $\mathrm{C}_{35} \mathrm{H}_{3} \mathrm{Br}_{2} \mathrm{~N}_{2}: \mathrm{C}, 59.31 ; \mathrm{H} .3 .58: \mathrm{N}, 5.54 \%$.

Preparation of $\left\{\left[\mathrm{H}_{2} \mathrm{DBPMF}\right]^{2+}\left[\mathrm{CuCl}_{4}\right]^{2-} \cdot \mathrm{H}_{2} \mathbf{O}\right\}$. To a warm solution of intermediate [DBPMF] $[0.51 \mathrm{~g} .1 .0 \mathrm{mmol}]$ in DMF $(50 \mathrm{~mL})$ was added with stirring $\mathrm{CuCl}_{2}(0.16 \mathrm{~g} .1 .0$ mumol) and yellow-green depositions were observed inmediately. After two drops of hydrochloric acid [6 mol/L] were added into the mixture the depositions were dissolved and the solution became to clear yellow-green. The resulting yellow-green solution was filtered and the filtrate was evaporated at room temperature in air. Three days later. crystals suitable for an X-ray structure determination were obtained. IR: $v 3444$ (vs). 3351 (vs). 1617 (m), 1557 (m), 1422 (m). 1224 (w), 1067 (w). 990 (m). 818 (m), 593 (w),<smiles></smiles><smiles>Brc1ccc(C2(Cc3ccncc3)c3ccc(Br)cc3-c3ccc(Br)cc32)c(Br)c1</smiles> 
$473(\mathrm{~m}) \mathrm{cm}^{-1}$. Found: C. $40.98 ;$ H. 3.19: N, $3.76 \%$. Calc for $\mathrm{C}_{25} \mathrm{H}_{2}=\mathrm{Br}_{2} \mathrm{Cl}_{4} \mathrm{CuN}_{2} \mathrm{O}: \mathrm{C}, 41.04 ; \mathrm{H} .3 .03: \mathrm{N}, 3.83 \%$.

Crystal structure determination. The diffraction data were collected on a Enraf-Nonius CAD-4 diffractometer with graphite- monchromated $M o-K \alpha$ radiation $(\lambda=0.71073$ $\AA, T=293 \mathrm{~K}$ ). The technique used was (1)-scan with limits 1.48 to $28.33^{\circ}$. The structure of the title compound was solved by direct methods and refined by least-squares refinements on $F^{2}$ by using the SHELXTL ${ }^{15}$ software package. All non-hydrogen atoms were anisotropically refined. The hydrogen atom positions were fixed geometrically at calculated distances and allowed to ride on the parent carbon atoms. The weighting scheme. $w=1 /\left[\sigma^{\hat{2}}\left(F_{0}^{\hat{}}\right)+(0.0340 P)^{\hat{\hat{j}}}\right]$. where $P=\left(F_{0}{ }^{2}+2 F_{c}^{\hat{2}}\right) / 3$. The molecular graphics were plotted using SHELXTL. Atomic scattering factors and anomalous dispersion corrections were taken from Intemational Tables for $X$-ron Chstallograph: ${ }^{16}$

Crystallographic data for the structure reported here have been deposited with CCDC (Deposition No. CCDC-672341). These data can be obtained free of charge via http://www. ccdc.cam.ac.uk/conts/retrieving.htmll or fron $\mathrm{CCDC}, 12$ Union Road, Cambridge CB2 lEZ. UK, e-mail: depositácedc.cam. ac.uk.

Acknowledgments. This work was supported by Natural Science Foundation of Shandong Province (No. Z2007B0l. Y2007B14), P. R. China. Doctoral Fund of Shandong Province. P. R. China, (No. 2006BS01043) and Doctoral Fund of Qingdao University of Science \& Teclunology.

\section{References}

1. Manivannian. S.: Dhanuskodi. S.: Kirschbaumn. K.: Tiwari. S. K Crustal Growth \& Design 2005. 5. 1463.

2. Reinoso. S.: Vitoria. P.: Lezama. L.: Luque. A.: Gutiérrez-Zorrilla. J. M. Ihorg. Chem. 2003. 42.3709.

3. Mitzi, D. B.: Brock. P. Horg. Chem. 2001. $40,2096$.

4. Adams. C. J.; Angeloni. A.: Orpen. A. G.: Podesta. T. J.: Shore. B. Chstal Gow $\&$ Design 2006. 6. 411. and references therein.

5. Aullón. G: Bellamy. D.: Brammer. L:: Bruton. E. A.: Orpent. A. G. Chem. Conmun. 1998, 653 .

6. Rivas. J. C. M. Brammer. L. horg. Chem. 1998. 37. 4756.

7. Lewis, G. R.; Orpen, A. G. Chem Commun 1998, 1873.

8. Gillon. A. L.: Lewis. G. R.: Orpent. A. G.: Rotter. S.: Starbuck. J.: Wang. X. M.: Rodriguez-Martin. Y.: Ruiz-Perez. C. J. Chem. Soc., Dalton Trams. 2000.3897.

9. Dolling, B.; Gillon. A. L.; Orpen, A. G.: Starbuck, J.: Wang, X. M. Chem. Conmun. $2001,567$.

10. Podesta, T. J.: Orpen, A. G. Coyst. Eng. Conm 2002, f, 336

11. Crawford. P. C.: Gillon. A. L.: Green. T.: Orpen. A. G.: Podesta. T. J.: Pritchard. S. V. Crnst. Eng Comm. 2004. 6, 419.

12. Angeloni. A.: Crawford. P. C.: Orpen. A. G.: Podesta. I. J.: Shore. B. J. Chem. Ew: J. 2004, 10,3783.

13. Dyrek, K: Goslar, J.: Hodorowicz, S. A; Hoftmann, S. K: Oleksyn, B. J.; Weselucha-Birczynski, A. Inorg. Chem. 1987. 26. 1481 .

14. Bond. M. R.: Iohnson1. T. J.: Willett. R. D. Can. J. Chem. 1988. 66.963.

15. Sheldrick, G. M. SHELITL I5.1 Software Reference Manuat, Bruker AXS. Ine; Madison, Wisconsin. USA. 1997.

16. Wilson. A. J. Intemational Table for I-rav Crystallography; Kluwer Academic Publishers: Dordrecht. 1992: Vol. C. Tables 6.1.1.4 (pp. 5(0)-5(02) and 4.2.6.8 (pp. 219-222). respectively. 